\title{
Stent migration after stent-in-stent technique using a biodegradable stent
}

Self-expanding metal stents (SEMS) seem to be the optimal choice for benign esophageal disorders, especially those not associated with a stricture, such as anastomotic leaks, iatrogenic perforations, and fistulas. On the other hand stent embedding can be an important limitation of SEMS placement, because this precludes safe stent removal [1]. In fact, in the literature there are only a few case series reporting the stent-in-stent technique using SEMS to remove embedded stents (14189 days from the placement of the first stent) $[2,3]$.

We report a case of a 65-year-old woman who underwent total gastrectomy for adenocarcinoma and, 3 months later, dilation of an anastomotic fibrotic stricture complicated by a visceral tear and sepsis. This was treated by placement of an Ultraflex stent (Boston Scientific, Natick, Massachusetts, USA). After 6 months, the patient complained of dysphagia, and a second longer Ultraflex stent was placed inside the first one ( $\bullet$ Fig. 1 ).

Because of the worsening of the patient's dysphagia in the preceding 6 months, the patient was referred to our division. Over a 2-month period, the patient underwent two treatments of argon plasma coagulation to reduce the reactive tissue and granulomatosis involving the not-covered esophageal proximal end of the stent, with partial reduction of her dysphagia $(\bullet$ Fig. 2 and $\odot$ Fig. 3 ). We decided to remove the internal stent and place a biodegradable SX-ELLA BD stent (ELLA-CS, Milady Horakove, Czech Republic), overlapping the proximal segment of the first stent, in order to improve the patient's quality of life ( $\mathbf{F i g . 4}$ ). The endoscopic checks at 15 and 45 days from stenting showed correct positioning and integrity of both the biodegradable and Ultraflex stents. At the third endoscopic check, after 3 months, neither stent was in place and the esophageal mucosa was completely re-epithelizated. It appeared that the biodegradable stent had been entirely absorbed, while the Ultraflex stent had migrated and been expelled with the stool because of pressure necrosis, arising from the biodegradable stent, of the overlying mucosa ( $\bullet$ Fig. 5). Two abdominal X-rays performed over 2 months confirmed the

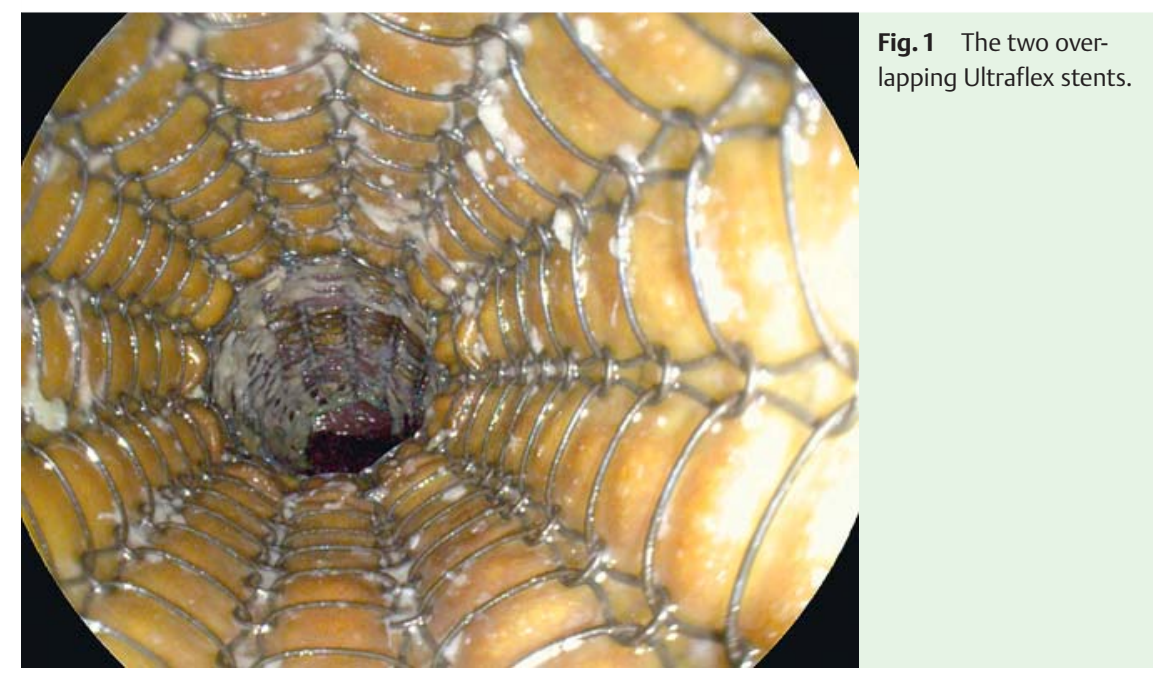

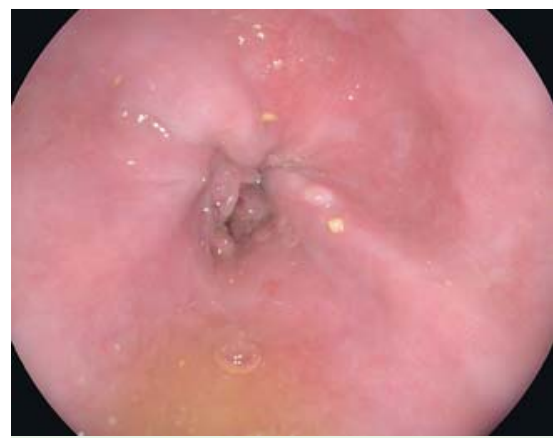

Fig. 2 Reactive tissue and granulomatosis involving the not-covered esophageal proximal end of the stent.

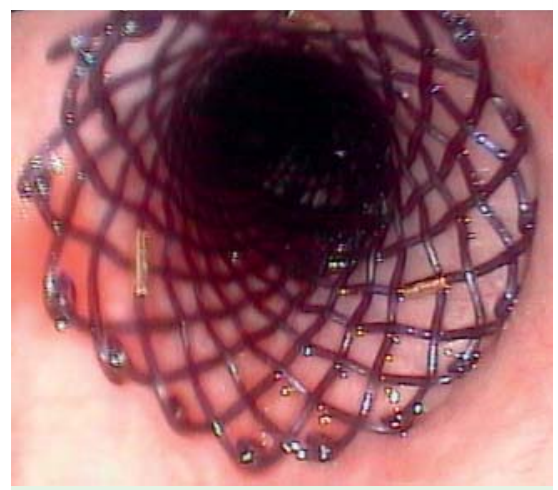

Fig. 4 Biodegradable SX-ELLA BD stent overlapping the proximal segment of the Ultraflex stent.

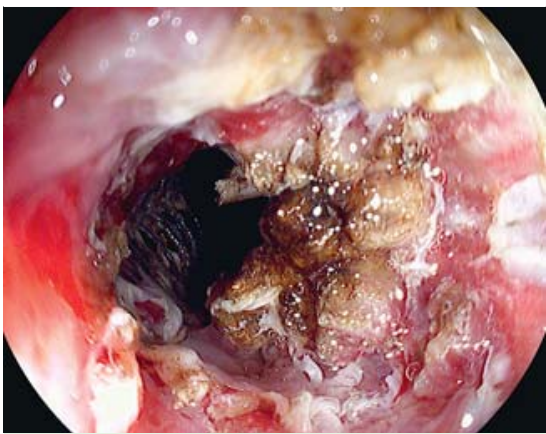

Fig.3 Endoscopic image after argon plasma coagulation.

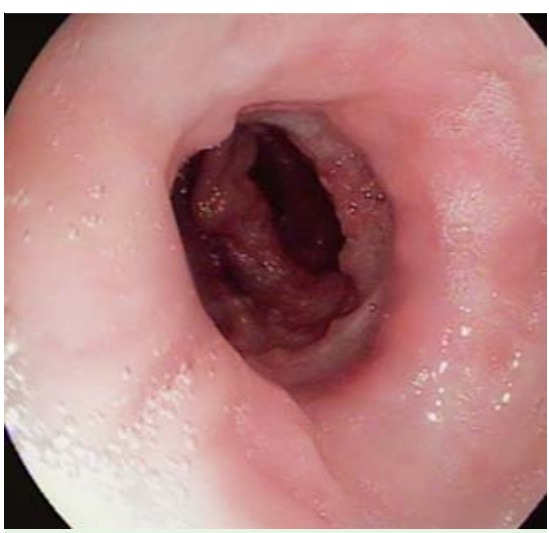

Fig. 5 Complete re-epithelization of the esophageal mucosa in the absence of the two stents. 


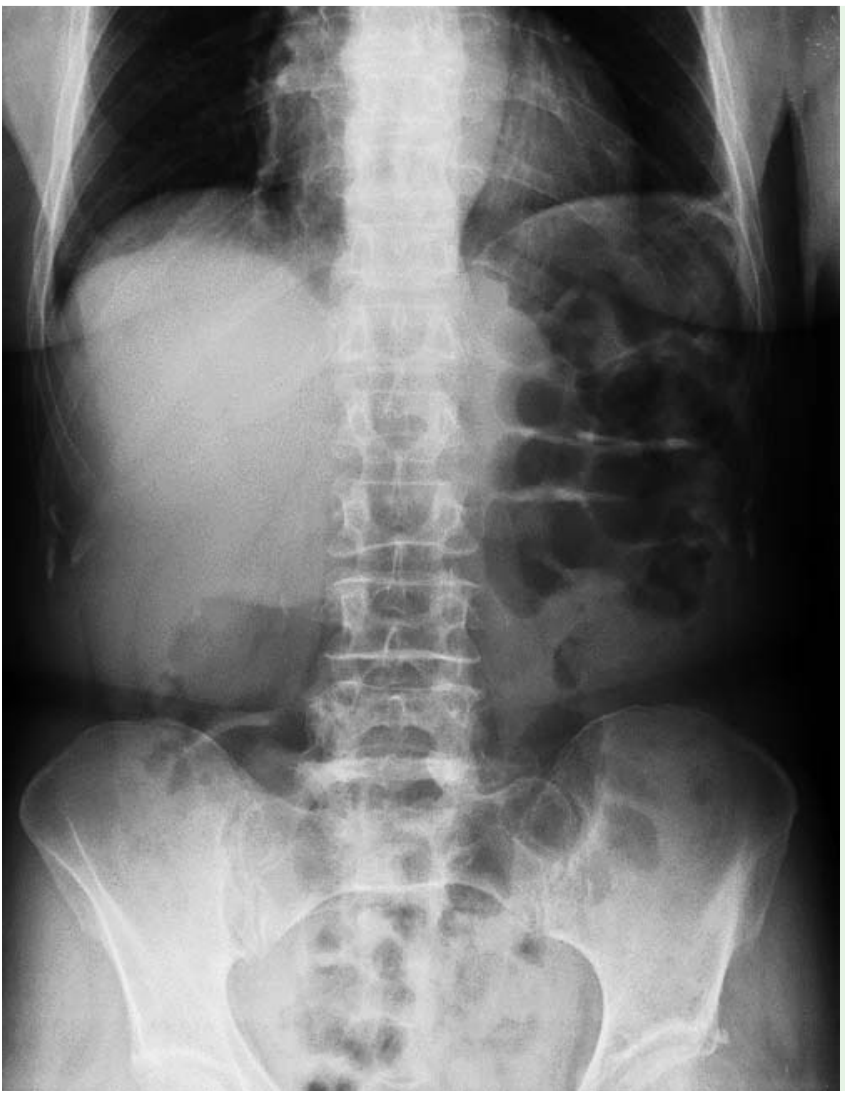

Fig. 6 Absence of radiopaque stent image at abdominal X-ray.

absence of radiopaque images relating to the first Ultraflex stent ( $\bullet$ Fig. 6 ). The patient's dysphagia disappeared, allowing her to follow an unrestricted diet and gain $15 \mathrm{~kg}$ in weight.

To our knowledge this is the first case reporting the stent-in-stent technique using a biodegradable stent with the unexpectment).

\section{Endoscopy_UCTN_Code_CPL_1AH_2AD}

\section{Competing interests: None}

\section{G. de Roberto, A. de Leone, \\ D. Tamayo, G. Fiori, D. Ravizza, \\ C. Trovato, S. De Lisi, C. Crosta}

Division of Endoscopy, European Institute of Oncology, Milan, Italy

\section{References}

1 Hirdes MM, Vleggaar FP, Van der Linde K et al. Esophageal perforation due to removal of partially covered self-expanding metal stents placed for a benign perforation or leak. Endoscopy 2011; 43: 156-159

2 Hirdes MM, Siersema PD, Houben MH et al. Stent-in-stent technique for removal of embedded esophageal self-expanding metal stents. Am J Gastroenterol 2011; 106: 286 293

3 Evrard S, Le Moine O, Lazaraki G et al. Selfexpanding plastic stents for benign esophageal lesions. Gastrointest Endosc 2004; 60: 894-900

\section{Bibliography}

DOI http://dx.doi.org/

10.1055/s-0031-1291526

Endoscopy 2012; 44: E51-E52

(c) Georg Thieme Verlag KG

Stuttgart · New York

ISSN 0013-726X

\section{Corresponding author}

\section{G. de Roberto, MD}

ed result of spontaneous and late migration of a metal stent (600 days after place-
Division of Endoscopy

European Institute of Oncology

Via Giuseppe Ripamonti 435

20141 Milan

Italy

Fax: +39-02-94379220

giuseppe.deroberto@ieo.it 